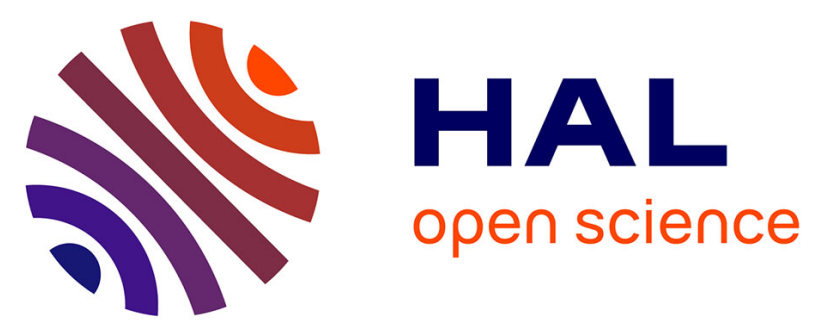

\title{
Difference in imaging biomarkers of neurodegeneration between early and late-onset amnestic Alzheimer's disease
}

\author{
Anne-Laure Aziz, Bernard Giusiano, Sven Joubert, Lauréline Duprat, Mira \\ Didic, Claude Gueriot, Lejla Koric, José Boucraut, Olivier Félician, \\ Jean-Philippe Ranjeva, et al.
}

\section{To cite this version:}

Anne-Laure Aziz, Bernard Giusiano, Sven Joubert, Lauréline Duprat, Mira Didic, et al.. Difference in imaging biomarkers of neurodegeneration between early and late-onset amnestic Alzheimer's disease. Neurobiology of Aging, 2017, 54, pp.22-30. 10.1016/j.neurobiolaging.2017.02.010 . hal-02479843

\section{HAL Id: hal-02479843 https://hal.science/hal-02479843}

Submitted on 6 Apr 2020

HAL is a multi-disciplinary open access archive for the deposit and dissemination of scientific research documents, whether they are published or not. The documents may come from teaching and research institutions in France or abroad, or from public or private research centers.
L'archive ouverte pluridisciplinaire HAL, est destinée au dépôt et à la diffusion de documents scientifiques de niveau recherche, publiés ou non, émanant des établissements d'enseignement et de recherche français ou étrangers, des laboratoires publics ou privés. 
Difference in imaging biomarkers of neurodegeneration between early and late-onset amnestic Alzheimer's disease.

Anne-Laure AZIZ (MD) ${ }^{1}$, Bernard GIUSIANO (MD) ${ }^{1,8}$, Sven JOUBERT (PhD) ${ }^{9,10}$, Lauréline DUPRAT ${ }^{4}$, Mira DIDIC (MD) ${ }^{1,5}$, Claude GUERIOT (MD) ${ }^{5}$, Lejla KORIC (MD) ${ }^{5}$, José BOUCRAUT (MD) ${ }^{3,11}$, Olivier FELICIAN (MD, PhD) $)^{1,5}$, Jean-Philippe RANJEVA (PhD) ${ }^{4}$, Eric GUEDJ (MD, PhD) ${ }^{2,6,7}$ and Mathieu CECCALDI (MD, $\mathrm{PhD})^{1,5}$

${ }^{1}$ Aix-Marseille Université, INSERM UMR 1106, Institut de Neurosciences des Systèmes, 13005 Marseille, France

${ }^{2}$ Service de Médecine Nucléaire, Assistance Publique-Hôpitaux de Marseille, Timone Hospital, 13385 Marseille, France

${ }^{3}$ Laboratoire d'Immunologie et d'Immunopathologie, Assistance Publique-Hôpitaux de Marseille, 13005 Marseille, France

${ }^{4}$ Aix-Marseille Université, Centre de Résonance Magnétique Biologique et Médicale CRMBM, UMR 7339 AMU-CNRS, 13385 Marseille, France

${ }^{5}$ Service de Neurologie et de Neuropsychologie \& CMRR PACA Ouest, AP-HM, 13385 Marseille, France

${ }^{6}$ Institut de Neurosciences de la Timone, UMR 7289, Aix-Marseille Université \& CNRS, Assistance Publique-Hôpitaux de Marseille, 13005 Marseille, France

${ }^{7}$ CERIMED, Aix-Marseille Université, 13005 Marseille, France

${ }^{8}$ APHM, Public Health Department, 13005 Marseille, France

${ }^{9}$ Département de psychologie, Université de Montréal, Montréal, Quebec, Canada 
${ }^{10}$ Centre de recherche Institut universitaire de gériatrie de Montréal (CRIUGM), Montréal, Quebec, Canada

${ }^{11}$ Aix Marseille Université, CRN2M, CNRS UMR 7286, 13344 Marseille Cedex 15, France.

Correspondance to: Dr Anne-Laure Aziz, Aix-Marseille Université, INSERM, Institut de Neurosciences des Systèmes, Faculté de Médecine, 27, Boulevard Jean Moulin, 13005

Marseille, France, anne-laure.aziz@hotmail.fr 


\section{ABSTRACT:}

Neuroimaging biomarkers differ between patients with early-onset (EOAD) and late-onset Alzheimer's disease (LOAD). Whether these changes reflect cognitive heterogeneity or differences in disease severity is still unknown. This study aimed at investigating changes in neuroimaging biomarkers, according to the age of onset of the disease, in mild amnestic Alzheimer's disease (AD) patients with positive amyloid biomarkers in cerebrospinal fluid (CSF). Both patient groups were impaired on tasks assessing verbal and visual recognition memory. EOAD patients showed greater executive and linguistic deficits, while LOAD patients showed greater semantic memory impairment. In EOAD and LOAD, hypometabolism involved the bilateral temporoparietal junction and the posterior cingulate cortex. In EOAD, atrophy was widespread, including frontotemporoparietal areas, whereas it was limited to temporal regions in LOAD. Atrophic volumes were greater in EOAD than in LOAD. Hypometabolic volumes were similar in the two groups. Greater extent of atrophy in EOAD, despite similar extent of hypometabolism, could reflect different underlying pathophysiological processes, different glucose-based compensatory mechanisms or distinct level of premorbid atrophic lesions. 
Key words: Alzheimer's disease; age of onset; neuroimaging biomarkers; magnetic resonance imaging; positron emission tomography imaging

\section{Abbreviations:}

AC-PC: anterior commissure-posterior commissure, ${ }^{18} \mathrm{FDG}=$ fluorodeoxyglucose, $\mathrm{MRI}=$ magnetic resonance imaging, $\mathrm{PET}=$ positron emission tomography imaging, $\mathrm{AD}=$ Alzheimer's disease, EOAD = early-onset Alzheimer's disease, LOAD = late-onset Alzheimer's disease, $\mathrm{KE}=$ cluster size (number of contiguous significant voxels), $\mathrm{BA}=$ Brodmann areas. 


\section{BACKGROUND:}

Alzheimer's disease (AD) is considered to be a memory disease of elderly patients, although it constitutes a polymorphic entity both in terms of its clinical presentation and age of onset. Early-onset Alzheimer's disease patients (EOAD) present with initial symptoms before the age of 65 (Delay J, 1962). Among the patients presenting with "typical" amnestic AD forms, differences in cognitive profiles (Joubert et al., 2016, Koedam et al., 2010) and functional brain connectivity (Gour et al., 2014) have been described based on age of onset of the disease. In EOAD patients, non-amnestic domains including executive functions, praxis, and visuoconstructional abilities, are more affected than in LOAD patients, suggesting a more diffuse pattern of cognitive impairment (Joubert et al., 2016). Concerning pathological data, Murray et al. reported that patients with hippocampal sparing and higher densities in neurofibrillary tangles in neocortical regions were the youngest ones, suggesting distinct agerelated clinicopathological subtypes of AD (Murray et al., 2011).

Structural MRI and ${ }^{18}$ FDG PET-CT are usually used as additional biomarkers for AD (Fan et al., 2008). These biomarkers provide information about morphological neural loss on the MRI, and functional neural changes of synaptic activity on ${ }^{18}$ FDG PET. Indeed, in the 'conventional' LOAD presentation, hypometabolism is believed to appear before atrophy in some of the brain regions involved early in the disease course, in particular in the posterior cingulate cortex (Bittner et al., 2005). Whether this temporal discrepancy between atrophy and hypometabolism observed in LOAD patients is similar in EOAD patients remains to be determined. 
Regarding the neuroimaging differences between EOAD and LOAD patients, previous studies suggested that EOAD patients have more widespread atrophy in neocortical structures than LOAD patients (Frisoni et al., 2005). At mild stages of dementia, the pattern of hypometabolism seems to involve the temporoparietal junction and posterior cingulate cortex in both EOAD and LOAD patients, whereas frontal hypometabolism seems to be greater in the former group (Salmon et al., 2000). However, inclusion of inhomogeneous clinical dementia presentations in previous studies might account for some of the variability in neuroimaging findings and limit conclusions about the reported differences, since shorter disease evolution and the atypical clinical presentations observed in EOAD can impact the neuroimaging patterns. To our knowledge, direct comparison between atrophic and hypometabolic areas from homogeneous EOAD and LOAD patient groups in terms of clinical phenotypes and dementia stages is not available.

Beyond topographic concerns, the question arises as to whether these macroscopic abnormalities differ in extent according to age of onset. Since several factors related to age of onset impact the expression of imaging biomarkers- such as disease severity, cognitive reserve or the preexisting atrophy level, we hypothesize differences between EOAD and LOAD patients concerning the atrophy volumes and hypometabolism.

The aim of the present study was to analyze the neuroimaging changes observed in $A D$, in terms of topography and extent according to age of onset in a single and homogeneous group of patients with amnestic mild AD.

\section{METHODS:}




\section{Subjects:}

The study uses data from the French hospital clinical research program ADAge (AP-HM, Marseille, France; PHRC National - 2008/24). Inclusion of patients and controls ranged from 2008 to 2015 at the cognitive neurology unit of CHU Timone, Marseille. All patients presented with typical amnestic AD according to criteria defined by McKhann 2011 (McKhann et al., 2011). All patients were at mild stages of dementia with a clinical dementia rate (CDR) of 1 . First symptoms of the disease, as reported by the patient and/or the family, appeared less than 5 years before the inclusion. Amyloid biomarkers in the CSF were positive for all patients (decrease in $\mathrm{A} ß 1-42$, below $500 \mathrm{pg} / \mathrm{mL}$ and an increase in Tau and phosphoTau, respectively above 450 and $60 \mathrm{pg} / \mathrm{mL}$ ). Patients were not included when the clinical presentation was atypical (primary progressive aphasia, posterior cortical atrophy, or a behavioral presentation), if they had neurological events in their past medical history, or if they met diagnostic criteria of other neurodegenerative diseases such as Fronto-Temporal Lobar Degeneration or Lewy Body Disease. Patients presenting one of the 4 following MRI criteria were not included: sequelae of stroke, more than 2 lacunes defined as an area of hyposignal bigger than $3 \mathrm{~mm}$ and circled by white or gray matter, presence of profound or periventricular white matter hyperintensities above grade 2 of Fasekas (Schmidt et al., 2007), or suspicion of recent ischemic stroke. Patients were matched for age and gender with healthy controls; all of them were classified into two groups, according to their age (above or below 65 years).

\section{Biological analysis:}

Apolipoprotein E genotype (Apo E) was obtained in all subjects using Hha 1 digestion and electrophoresis analysis. 
Patients had a lumbar puncture for AD CSF biomarkers (Aß1-42, Tau and phosphoTau protein, IATI score defined as Aß42/(240+1.18Tau).

\section{Neuropsychological assessment:}

All participants underwent a comprehensive clinical assessment, including a global assessment of quality of life (WHO-QOL 30 scale) and caregiver burden (Zarit scale) (Zarit et al., 1980) as well as neuropsychiatric symptoms (NPI-scale) (Cummings, 1997) and depressive signs (MADRS scale) (Montgomery et al., 1985), along with detailed neuropsychological measures. General cognitive abilities were assessed using the Minimental State Examination (MMSE) (Folstein et al., 1975) and the Batterie rapide d'évaluation frontale (BREF/FAB) (Dubois et al., 2000). Episodic memory (anterograde memory) was assessed both in the verbal and visual domains. Verbal memory was assessed with the delayed RL/RI 16 (Van der Linden and Juillerat, 2004), a free/cued word recall test widely used as a measure of verbal learning in French similar to the Free and Cued Selective Reminding Test (FCSRT) (Grober et al., 1988). Visual memory was assessed using the Delayed Matching to Sample test (DMS48), a visual recognition memory test widely used in the assessment of Mild Cognitive Impairment (MCI) and dementia (Barbeau et al., 2004). Semantic memory (retrograde memory) was assessed using the TOP 10 (Thomas-Antérion et al., 2006). The TOP 10 is a standardized semantic test evaluating famous person knowledge. Executive functions were assessed using the Trail Making Test part A (attention) and the Trail Making Test part B (Reitan, 1955). Language abilities were evaluated with the DO80, a French standardized picture naming task (Deloche et al., 1997) and the Category (animals) fluency test (Cardebat et al., 1990). The Benton line orientation test (BLOT) was employed to evaluate visuospatial abilities (Benton et al., 1978), while visuoconstructional abilities were assessed using the copy of the Rey-Osterrieth figure (Rey and de MORSIER, 1960). 


\section{Neuroimaging data:}

PET scans were performed using an integrated PET/CT camera (Discovery ST, GE Healthcare, Waukesha, WI) with an axial resolution of $6.2 \mathrm{~mm}$ allowing 47 contiguous transverse sections of the brain of $3.27 \mathrm{~mm}$ thickness. FDG (150 MBq) was injected intravenously with the subject in an awake and resting state with eyes closed in a quiet environment. Image acquisition was started $30 \mathrm{~min}$ after injection and ended $15 \mathrm{~min}$ later. Images were reconstructed using the ordered subset expectation maximization algorithm with five iterations and 32 subsets, and corrected for attenuation using a CT transmission scan.

Structural 3D MPRAGE T1 MRI acquisitions were performed in the CEMEREM unit, under the same conditions for all patients and controls. The MRI parameters were the following: 128 axial slices, slice thickness less than $1.25 \mathrm{~mm}, 256 x 256$ matrix, $\mathrm{RT}=1050 \mathrm{mS}, \mathrm{ET}=3.93$ $\mathrm{mS}, \mathrm{IT}=310 \mathrm{mS}, \mathrm{FA}=12^{\circ}, \mathrm{PB}=123 \mathrm{~Hz} /$ pixel.

\section{Biological and neuropsychological data analysis and statistics:}

Concerning the analysis of CSF biomarkers, the Innotest Amyloid Tau Index (IATI) was calculated as: (measured Aß1-42/(240+1.18 [Tau]). The cerebrospinal ratios between amyloid and Tau markers were obtained by dividing Aß1-42 respectively by Tau and phosphoTau concentrations.

Neuropsychological data in the two age groups were compared in reference to their respective adjusted healthy control group. Individual Z-scores were determined for neuropsychological data and calculated as follows: [(individual patient score - mean score of the matched control group)/ standard deviation of the matched control group]. 
Between-group comparisons were performed using respectively a Student t-test in the case of normal data distributions and a Mann-Whitney test in the case of non-normal distributions. The statistical analysis was performed using PrismGraphPad®. A Bonferroni correction was applied, resulting in a p signification level of 0.001 .

\section{Imaging data analysis:}

DICOM data were converted in NIFTI images using the publicly available "MRICron" software (http://www.sph.sc.edu/comd/rorden/mricron/). Whole brain group comparisons of EOAD versus LOAD patients and of patients versus age-matched controls were performed using SPM12 (Wellcome Department of Cognitive Neurology, University College, London, UK, fil.ion.ucl.ac.uk/spm) for both PET and MRI data. The PET and MRI images were realigned, AC-PC reoriented and spatially normalized into the MNI space. All images were smoothed at $8 \mathrm{~mm}$ full-width at half-maximum (FWHM) with a Gaussian filter. The proportional scaling normalization was used. A T-score threshold was applied for PET and MRI analyses despite distinct numbers of voxels tested. The cluster size was set to be higher than the expected volume based on random field theory and provided by the SPM model (for MRI and PET). A 3.16 T-score corresponding to a p significant level of 0.001, corrected for gender and educational level and a cluster size equal or above 125 or 65 voxels were considered as significant for PET and MRI analysis, respectively, in the comparisons of EOAD vs LOAD. A 3.16 T-score and a cluster size equal or above 300 voxels corrected for age, gender and level of education was considered as significant for the comparisons of patients versus controls. This last threshold defined regions of hypometabolism and nonhypometabolism, and of atrophy and non-atrophy, in each group of patients in comparison to respective healthy group. The anatomical localization of the most significant voxels was then identified using Talairach Daemon (http://ric.uthscsa.edu/projects/talairachdaemon.html). In 
comparison to healthy subjects, a brain cartography of atrophic and/or hypometabolic regions, resulting from successive masks applied to the PET or MRI images, was then performed and illustrated on a 3D brain render using MRICron software. In this line, regions of pure hypometabolism (defined as areas of significant hypometabolism without significant atrophy), were searched within the mask of non-atrophy. The same process was used to define the pure atrophic regions (within the mask of non-hypometabolism). The respective volumes (in $\mathrm{mm}^{3}$ ) of atrophic and hypometabolic regions, concerning the whole cortex, were determined by using MarsBar toolbox in SPM (http://marsbar.sourceforge.net/).

\section{RESULTS:}

\section{Population description: clinical data and general scales}

Twenty-three EOAD patients and 29 LOAD patients were included and adjusted for age with respectively 19 young controls (YCTRL) and 33 old controls (OCTRL).

Mean age was respectively 60.2 and 77.0 years for EOAD and LOAD patients. Respective female/male ratio was 0.60 and 0.62 for EOAD and LOAD patients. Educational levels in years of formal education were respectively, for EOAD, LOAD, YCTRL and OCTRL, of 11.3 (3), 10.3 (4.2), 13 (2) and 12.2 (3.7). EOAD and LOAD patients obtained very similar results concerning the following scales: WHO-QOL30 (Quality of life assessment), NPI (neuropsychiatric symptoms), MADRS (depressive symptoms), Zarit (caregiver burden) (table 1). 


\begin{tabular}{ccccc}
\hline & EOAD & LOAD & YCTRL & OCTRL \\
\hline Age (years) & $60.2(5.3)$ & $77(4.7)$ & $56(7)$ & $74(5.6)$ \\
\hline Sex (W/M) & $14 / 9$ & $18 / 11$ & $14 / 5$ & $21 / 11$ \\
\hline Education (years) & $11.3(3)$ & $10.3(4.2)$ & $13(2)$ & $12.2(3.7)$ \\
\hline NPI & $15,7(14,6)$ & $14,1(14,6)$ & NA & NA \\
\hline MADRS & $7(6,3)$ & $7,1(6,1)$ & NA & NA \\
\hline Zarit & $17,8(17,5)$ & $16,3(14,5)$ & NA & NA \\
\hline WHO-QOL 30 & $15,8(3,2)$ & $15,8(3,8)$ & NA & NA
\end{tabular}

Table 1: Epidemiological, neuropsychiatric and quality of life assessment in patients and controls. NA is mentioned when data was not available or not applicable.

\section{Biological data:}

Concerning CSF biomarkers for $\mathrm{AD}$, levels of $\mathrm{A} ß 1-42$ were slightly but not significantly lower in LOAD compared to EOAD patients, respectively 337 (112) vs 417 (137) pg/mL, $\mathrm{p}=0.02$. The other biomarkers showed similar rates in both groups (table 2).

Concerning Apo E genotype, there were more Apo E4 carriers in EOAD (90.5\%) than in LOAD patients $(44.8 \%), \mathrm{p}<0.0001$ and in controls $(9.7 \%), \mathrm{p}<0.0001$ (table 2). There were 3 homozygote patients in the EOAD group (15\%), versus 0 in the LOAD group. 


\begin{tabular}{|c|c|c|c|c|c|c|c|}
\hline & EOAD & LOAD & YCTRL & OCTRL & $\begin{array}{c}\text { EOAD } \\
\text { vs YCTRL }\end{array}$ & $\begin{array}{l}\text { LOAD vs } \\
\text { OCTRL }\end{array}$ & $\begin{array}{c}\text { EOAD } \\
\text { vs LOAD }\end{array}$ \\
\hline \multicolumn{8}{|l|}{$\begin{array}{c}\text { Biomarkers } \\
(\mathrm{pg} / \mathrm{mL})\end{array}$} \\
\hline Aß1-42 & 417 (137) & $337(112)$ & NA & NA & NA & NA & $p=0.02$ \\
\hline Tau & $550(255)$ & $530(290)$ & NA & NA & NA & NA & $p=0.8$ \\
\hline PhosphoTau & $97(30)$ & $85(34)$ & NA & NA & NA & NA & $p=0.2$ \\
\hline IATI & $0.5(0.1)$ & $0.4(0.2)$ & NA & NA & NA & NA & $p=0.15$ \\
\hline Aß1-42 / Tau & $0.8(0.3)$ & $0.8(0.4)$ & NA & NA & NA & NA & $p=0.55$ \\
\hline Aß1-42 / phTau & $4.9(2.4)$ & $4.5(2)$ & NA & NA & NA & NA & $p=0.7$ \\
\hline \multicolumn{8}{|l|}{ E Apo's genotype } \\
\hline ApoE4+ (N; \%) & $19 ; 90.5$ & $13 ; 44.8$ & $1 ; 5.5$ & $3 ; 9.7$ & $<0.0001$ & $<0.0001$ & $<0.0001$ \\
\hline ApoE4- (N; \%) & $2 ; 9.5$ & $16 ; 55.2$ & $17 ; 94.5$ & $28 ; 90.3$ & & & \\
\hline
\end{tabular}

Table 2: Apolipoprotein $\mathbf{E}$ genotype and cerebrospinal fluid biomarkers in patients and controls. Statistical significance is set at $p<0.001$. NA is mentioned when data was not available or not applicable. 


\section{Neuropsychological tests:}

EOAD and LOAD patients were impaired on neuropsychological tests when compared to their respective control groups, in particular for the MMSE, memory tasks (RL-RI 16, DMS48, TOP10), visuoconstructional tests (Copy of the Rey-Osterrieth figure for EOAD patients), executive function tests (TMT A and B) and language tests (DO80 for LOAD patients, Category fluency), $(\mathrm{p}<0.001)$ (table 3). Thus, both patient groups showed very similar overall cognitive profiles, such as typically reported in the mild dementia stage of AD.

\begin{tabular}{|c|c|c|c|c|c|c|c|}
\hline & & EOAD & LOAD & YCTRL & OCTRL & $\begin{array}{l}\text { EOAD } \\
\text { vs } \\
\text { YCTRL } \\
\text { (p) }\end{array}$ & $\begin{array}{l}\text { LOAD } \\
\text { vs } \\
\text { OCTRL } \\
\text { (p) }\end{array}$ \\
\hline & MMSE (/30) & $\begin{array}{c}20,30 \\
(3.6)\end{array}$ & $\begin{array}{r}21,90 \\
(3.8)\end{array}$ & $\begin{array}{c}29,32 \\
(0.8)\end{array}$ & $\begin{array}{c}29,15 \\
(0.6)\end{array}$ & $\begin{array}{c}< \\
0,001 \\
\ddagger\end{array}$ & $\begin{array}{c}< \\
0,001 \\
\ddagger\end{array}$ \\
\hline \multirow[t]{3}{*}{ MEMORY } & $\begin{array}{c}\text { Delayed RL/RI } \\
(/ 16)\end{array}$ & $\begin{array}{r}2,727 \\
(4.1)\end{array}$ & $\begin{array}{l}3,769 \\
(4.5)\end{array}$ & $\begin{array}{l}15,95 \\
(0.2)\end{array}$ & $\begin{array}{c}15,64 \\
(0.8)\end{array}$ & $\begin{array}{c}< \\
0,001 \\
\ddagger\end{array}$ & $\begin{array}{c}< \\
0,001 \\
\ddagger\end{array}$ \\
\hline & DMS48 (\%) & $\begin{array}{l}83,86 \\
(14.5)\end{array}$ & $\begin{array}{l}73,46 \\
(15.8)\end{array}$ & $\begin{array}{l}96,05 \\
(4.4)\end{array}$ & $\begin{array}{c}94,39 \\
(7.6)\end{array}$ & $\begin{array}{c}< \\
0,001 \\
\ddagger\end{array}$ & $\begin{array}{c}< \\
0,001 \\
\ddagger\end{array}$ \\
\hline & TOP10 & $\begin{array}{c}24,5 \\
(13,1)\end{array}$ & $\begin{array}{c}18,2 \\
(12,2)\end{array}$ & $\begin{array}{l}50,8 \\
(6,8)\end{array}$ & $\begin{array}{l}49,5 \\
(7,5)\end{array}$ & $\begin{array}{c}< \\
0.001\end{array}$ & $\begin{array}{c}< \\
0.001\end{array}$ \\
\hline \multirow[t]{2}{*}{$\begin{array}{l}\text { VISUOCONSTRUCTIONAL } \\
\text { ABILITIES }\end{array}$} & BLOT (/30) & $\begin{array}{c}18,00 \\
(18)\end{array}$ & $\begin{array}{c}19,76 \\
(4.8)\end{array}$ & $\begin{array}{l}22,84 \\
(22.8)\end{array}$ & $\begin{array}{c}23,52 \\
(3.8)\end{array}$ & $<0,01$ & $<0,01$ \\
\hline & $\begin{array}{c}\text { Rey copy score } \\
(/ 36)\end{array}$ & $\begin{array}{c}17,68 \\
(15)\end{array}$ & $\begin{array}{l}28,74 \\
(11.4)\end{array}$ & $\begin{array}{l}34,47 \\
(1.3)\end{array}$ & $\begin{array}{l}33,97 \\
(3)\end{array}$ & $\begin{array}{c}< \\
0,001 \\
\ddagger\end{array}$ & $\begin{array}{l}0,02 \\
\ddagger\end{array}$ \\
\hline \multirow[t]{3}{*}{ EXECUTIVE FUNCTIONS } & FAB (/18) & $\begin{array}{c}12,39 \\
(3.1)\end{array}$ & $\begin{array}{c}12,52 \\
(3.7)\end{array}$ & $\begin{array}{l}17,58 \\
(0.8)\end{array}$ & $\begin{array}{c}17,45 \\
(0.8)\end{array}$ & $\begin{array}{c}< \\
0,001 \\
\ddagger\end{array}$ & $\begin{array}{c}< \\
0,001 \\
\ddagger\end{array}$ \\
\hline & TMTA & $\begin{array}{c}75,50 \\
(43)\end{array}$ & $\begin{array}{l}115,1 \\
(151)\end{array}$ & $\begin{array}{l}33,32 \\
(10.2)\end{array}$ & $\begin{array}{l}46,64 \\
(15.4)\end{array}$ & $\begin{array}{c}< \\
0,001 \\
\ddagger\end{array}$ & $\begin{array}{c}< \\
0,001 \\
\ddagger\end{array}$ \\
\hline & TMTB & $\begin{array}{c}248,1 \\
(98)\end{array}$ & $\begin{array}{c}203,9 \\
(77)\end{array}$ & $\begin{array}{c}72,74 \\
(17)\end{array}$ & $\begin{array}{c}110,3 \\
(38)\end{array}$ & $\begin{array}{c}< \\
0,001\end{array}$ & $\begin{array}{c}< \\
0,001 \\
\ddagger\end{array}$ \\
\hline \multirow[t]{2}{*}{ LANGUAGE } & D080 (/80) & $\begin{array}{c}73,70 \\
(5.4)\end{array}$ & $\begin{array}{l}68,14 \\
(17.1)\end{array}$ & $\begin{array}{c}73,70 \\
(5.4)\end{array}$ & $\begin{array}{c}79,55 \\
(1.4)\end{array}$ & $\begin{array}{c}> \\
0,9999\end{array}$ & $\begin{array}{c}< \\
0,001 \\
\ddagger\end{array}$ \\
\hline & $\begin{array}{l}\text { Category } \\
\text { fluency }\end{array}$ & $\begin{array}{c}14,39 \\
(6.6)\end{array}$ & $\begin{array}{c}14,21 \\
(7.7)\end{array}$ & $\begin{array}{c}31,11 \\
(5.2)\end{array}$ & $\begin{array}{c}29,00 \\
(6.3)\end{array}$ & $\begin{array}{c}< \\
0,001\end{array}$ & $\begin{array}{c}< \\
140,001\end{array}$ \\
\hline
\end{tabular}




\section{ACCEPTED MANUSCRIPT}

Table 3: Neuropsychological results (raw scores) in patients and controls.

Statistical significance degree is set at $\mathrm{p}<0.001$. “ $\neq ”$ highlights Mann-Whitney test.

However, EOAD patients showed significantly lower scores, as expressed by individual Zscores, than LOAD patients on the Copy of the Rey-Osterrieth figure, and on the TMT B $(p<0.001)$. EOAD patients showed lower results compared with LOAD patients on the DO80 and Category Fluency, although not significant following Bonferroni corrections $(\mathrm{p}<0.01)$. Finally, LOAD patients showed significantly lower results than EOAD ones on TOP10 $(\mathrm{p}<0.001)($ table 4).

\begin{tabular}{|c|c|c|c|c|}
\hline & & EOAD & LOAD & $\begin{array}{l}\text { EOAD vs LOAD } \\
\text { (p) }\end{array}$ \\
\hline & MMSE & $-9,966(4.8)$ & $-11.7(6.1)$ & $0.43 \ddagger$ \\
\hline \multirow[t]{3}{*}{ MEMORY } & Delayed RL/RI & $-59.2(17.8)$ & $-15.1(5.7)$ & $<0.001 \mp$ \\
\hline & DMS48 & $-3.2(3.3)$ & $-2.7(2.1)$ & $0.7 \ddagger$ \\
\hline & TOP10 & $-1.5(0.8)$ & $-2.7(1.1)$ & $<0.001$ \\
\hline \multirow{2}{*}{$\begin{array}{l}\text { VISUOCONSTRUCTIONAL } \\
\text { ABILITIES }\end{array}$} & Benton Lines & $-1.4(1.6)$ & $-0.9(1.2)$ & 0.33 \\
\hline & $\begin{array}{l}\text { Rey's copy } \\
\text { score }\end{array}$ & $-1.7(1.8)$ & $-0.03(0.7)$ & $<0.001 \ddagger$ \\
\hline \multirow[t]{3}{*}{ EXECUTIVE FUNCTIONS } & BREF & $-1.34(0.8)$ & $-1.2(0.8)$ & 0.4 \\
\hline & TMTA & $-3.4(3.6)$ & $-4.4(9.8)$ & $0.43 \ddagger$ \\
\hline & TMTB & $-8.9(5.1)$ & $-2.4(2.0)$ & $<0.001 \ddagger$ \\
\hline \multirow[t]{2}{*}{ LANGUAGE } & D080 & $-28.8(31)$ & $-8.2(12.3)$ & $<0.01 \ddagger$ \\
\hline & $\begin{array}{l}\text { Category } \\
\text { Fluency }\end{array}$ & $-3.2(1.3)$ & $-2.3(1.2)$ & $<0.01 \mp$ \\
\hline
\end{tabular}

Table 4: Comparison of neuropsychological Z-scores between EOAD and LOAD patients.

Statistical significance degree is $\mathrm{p}<0.001$. “ $¥ ”$ highlights Mann-Whitney test. 


\section{Neuroimaging:}

Direct comparison between EOAD versus LOAD:

Intergroup metabolic comparison showed more hypometabolism in EOAD patients than in LOAD in bilateral cuneus, in left precuneus (BA 19) and in the right middle temporal gyrus. It showed more hypometabolism in LOAD patients than in EOAD in the right limbic lobe (BA 28) and right inferior temporal gyrus (BA 20).

Intergroup atrophy comparison showed more atrophy in EOAD patients than in LOAD in bilateral inferior (BA 40) and superior (BA 7) parietal lobule, in bilateral post central gyrus (BA 2) and in the middle temporal gyrus (BA 39). It showed more atrophy in the right orbitofrontal gyrus (BA 11), in the right limbic lobe (BA 20) and in the right superior temporal gyrus (BA 38). (Fig 1). 
Patients versus age-matched controls:

Intergroup metabolic comparison showed hypometabolism in the temporoparietal junction bilaterally $(\mathrm{T}$-score $=7.4, \mathrm{KE}=9386$ voxels $)$, and in the posterior cingulate cortex/precuneus in both $\mathrm{EOAD}(\mathrm{T}$-score $=6.8, \mathrm{KE}=9386$ voxels $)$ and $\mathrm{LOAD}$ patients $(\mathrm{T}$-score $=6.1, \mathrm{KE}=$ 4660 voxels). In the latter patient group, hypometabolism also involved temporal areas (anterior, superior and inferior temporal areas). Intergroup comparison showed significant atrophy, limited to bilateral temporal regions (for superior temporal region, $\mathrm{T}$-score $=5.9$, $\mathrm{KE}=615$ voxels, for inferior temporal region, $\mathrm{T}$-score $=5.9, \mathrm{KE}=1161$ voxels $)$, in $\mathrm{LOAD}$ patients. Atrophy was more widespread in EOAD patients, involving the prerolandic and retrorolandic associative neocortex, in particular parietal $(\mathrm{T}$-score $=5.6, \mathrm{KE}=624$ voxels $)$ and smaller frontal regions (table 5 and Fig.2).

\begin{tabular}{|c|c|c|c|c|c|c|c|c|}
\hline & & $\begin{array}{c}\text { Cluster- } \\
\text { level }\end{array}$ & $\begin{array}{l}\text { Peak- } \\
\text { level }\end{array}$ & & Talairach & & BA & Side, Gyrus \\
\hline & & KE & $\mathbf{T}$ & $\begin{array}{c}X \\
(\mathrm{~mm})\end{array}$ & $\mathrm{Y}(\mathrm{mm})$ & $\mathrm{Z}(\mathrm{mm})$ & & \\
\hline \multirow[t]{6}{*}{ PET } & \multirow{3}{*}{$\begin{array}{c}\text { EOAD } \\
\text { (vS } \\
\text { YCTRL) }\end{array}$} & 9386 & 7.4 & -44 & -60 & 38 & 40 & L, Inferior Parietal \\
\hline & & 9386 & 6.8 & -8 & -55 & 38 & 7 & L, Precuneus \\
\hline & & 1654 & 3.6 & 52 & -48 & 12 & 22 & $\begin{array}{l}\text { R, Superior } \\
\text { Temporal }\end{array}$ \\
\hline & \multirow{3}{*}{$\begin{array}{c}\text { LOAD } \\
\text { (vS } \\
\text { OCTRL) }\end{array}$} & 4660 & 6.1 & -36 & -68 & 42 & 19 & L, Precuneus \\
\hline & & 4660 & 5.7 & -58 & -46 & -16 & 37 & L, Inferior Temporal \\
\hline & & 2226 & 5.5 & -2 & -36 & 36 & 31 & $\begin{array}{l}\text { L, Posterior } \\
\text { Cingulate }\end{array}$ \\
\hline \multirow[t]{6}{*}{ MRI } & \multirow{3}{*}{$\begin{array}{c}\text { EOAD } \\
\text { (vS } \\
\text { YCTRL) }\end{array}$} & 3504 & 7.5 & -66 & -34 & -6 & 21 & L, Middle Temporal \\
\hline & & 1409 & 6.4 & -12 & -34 & 0 & 27 & L, Parahippocampal \\
\hline & & 624 & 5.6 & -36 & -56 & 54 & 40 & L, Inferior Parietal \\
\hline & \multirow{3}{*}{$\begin{array}{c}\text { LOAD } \\
\text { (vS } \\
\text { OCTRL) }\end{array}$} & 615 & 5.9 & -32 & 8 & -18 & 38 & $\begin{array}{l}\text { L, Superior } \\
\text { Temporal }\end{array}$ \\
\hline & & 1161 & 5.9 & -62 & -40 & -16 & 20 & L, Inferior Temporal \\
\hline & & 778 & 5.7 & 34 & -18 & -36 & 20 & L, Uncus \\
\hline
\end{tabular}


Table 5: Statistics and localization of the most significant results of intergroup PET and MRI comparison between patients and their respective healthy controls.

Results are given at the cluster-level and at the peak-level, False-Discovery Rate, minimal Tscore $=3.16$, minimal $\mathrm{KE}>300$ voxels. $\mathrm{KE}$ corresponds to the cluster size, $\mathrm{BA}=$ Brodmann area, $\mathrm{L}=$ Left, $\mathrm{R}=$ Right.

Differences concerning topography of pure hypometabolic or pure atrophic areas were found when comparing EOAD and LOAD patients (Fig.3). Pure hypometabolism was limited to the temporoparietal junction bilaterally in EOAD. It was more widespread in LOAD patients, involving the posterior and anterior temporal regions. The posterior cingulate cortex showed pure hypometabolism in the two groups. Pure atrophy was found in temporal but also frontal regions in EOAD patients, whereas it was limited to temporal structures in LOAD patients. Regions showing both significant hypometabolism and atrophy included the bilateral posterior temporal regions in EOAD patients, and middle temporal regions in LOAD patients.

Respective volumes of pure hypometabolism and pure atrophy on the entire brain are shown in Fig.4. EOAD patients had a greater volume of atrophy $(61000 \mathrm{~mm} 3)$ than LOAD patients (close to $14000 \mathrm{~mm} 3$ ). However, hypometabolism volumes were very close in EOAD and LOAD patients (65 $000 \mathrm{~mm} 3$ for EOAD and $59000 \mathrm{~mm} 3$ for LOAD patients). Both atrophic and hypometabolic regions are larger in EOAD patients than in LOAD ones (respectively 11 000 vs $5400 \mathrm{~mm} 3)$. 


\section{DISCUSSION:}

The main goal of this study was to compare age of onset-related differences in structural and metabolic imaging patterns, in a homogeneous group of patients presenting with an amnestic mild AD, selected on the basis of a positive CSF AD biomarker profile. We showed a shift between EOAD and LOAD patients concerning the topography but also, for the first time, concerning the extent of these biomarker abnormalities.

We included a homogeneous group of patients in order to avoid clinical phenotype variability that could act as a confounding factor for imaging analysis. Although memory impairment was found in the two groups, differences were observed on other neuropsychological tests, suggesting, in accordance with previous studies, that some neuropsychological functions are differently affected by the disease as a function of age of onset (Binetti et al., 1993). Direct Zscore comparisons between EOAD and LOAD patients showed distinct severity: EOAD patients were more impaired in executive, attentional, linguistic and visuoconstructional functions, whereas LOAD patients were more impaired in semantic memory. This might reflect, at least at this mild dementia stage, a greater dysfunction of associative neocortical areas in EOAD patients. Conversely, LOAD patients were more severely impaired on longterm memory, which is likely due to greater underlying damage of temporal lobe structures (Joubert et al., 2016).

In our study EOAD patients carried in a greater proportion the Apolipoprotein E4 allele than LOAD patients. There were 3 patients with an e4 homozygotes profile in the EOAD group (15\%), versus none in the LOAD group. This over-representation of E4 alleles in the EOAD group may be due to the specific selection criteria with the exclusion of atypical forms of AD and could indicate a selection bias. Previous studies showed controversial results regarding 
the frequency of E4 carriers according to the age of onset, and the effect of the Apolipoprotein E genotype on imaging data and clinical profiles. AD has been reported to be dependent on the age among the ApoE4-carriers (Farrer et al., 1997), with a maximum impact between 60 and 70 years (Davidson et al., 2007). In EOAD, Smits et al. showed a faster decline in non-memory cognitive functions in non-carrier patients (Smits et al., 2015). A positive correlation between E4-carriers and mesiotemporal atrophy, together with memory dysfunction, has been suggested in LOAD patients. However, other authors hypothesized that the clinical profile of EOAD patients is particularly determined by genetic factors, including Apolipoprotein E genotype, whereas the profile of LOAD patients profile appears to be more influenced by environmental factors (Frisoni et al., 2005). E4 allele is known to be associated with earlier disease onset (Slooter et al., 1998, Thambisetty et al., 2013). The role of other potential genetic factors on the age of onset is still unknown. Other studies would be relevant in this field, to better understand the links between E4 carriers, age at onset and clinical and neuroimaging expression.

Structural MRI and 18FDG PET are classically used in addition to CSF biomarkers (Bittner et al., 2005) and their patterns are well defined, especially in LOAD (Good et al., 2001, Herholz et al., 2002, Matsuda et al., 2002) . However, these neuroimaging patterns are characterized by heterogeneity (Chételat et al., 2008) and are impacted by several factors, including age of onset (Frisoni et al., 2007).

For a mild level of dementia, and an amnestic presentation, we observed widespread atrophy in EOAD patients, including pre and retrorolandic areas, whereas atrophy was limited to 
temporal regions in LOAD patients. This was observed based on the results of a comparison between EOAD and LOAD and a comparison between patients and controls. Very little changes in metabolic abnormalities were observed between EOAD and LOAD. Hypometabolism involved temporal areas bilaterally in EOAD and LOAD, yet extended to the anterior temporal region in LOAD patients. Precuneus and cuneus areas were more hypometabolic in EOAD patients. As opposed to previous authors, we did not identify significant frontal hypometabolism in EOAD patients (Kalpouzos et al., 2005). This might be related to the inclusion of patients in a more advanced disease stage in previous studies. These neuroimaging findings might reflect underlying pathological differences between EOAD and LOAD patients. We hypothesize that neuroimaging biomarker expression depends on the spread of neurofibrillary tangles (NFT), which differ between EOAD and LOAD patients. Murray et al. suggested that Braak \& Braak stages couldn't be fully applied to EOAD patients (Braak and Braak, 1991) whose NFT involve neocortical areas at an earlier stage (Murray et al., 2011). These pathological results could be further assessed using in-vivo Tau markers in PET-CT, in particular at the earliest stages of the disease. Little is known about the determinants of brain regions vulnerability to amyloid and tau induced phenomena. Freer et al. suggested that tissue vulnerability may be mediated by failures of the protein homeostasis system and variability in tissue connectivity (Freer et al., 2016). Age of onset might influence the topography of abnormal protein aggregation, with the highest tissue vulnerability in neocortical regions in EOAD and in limbic cortex in LOAD patients, in line with our results. Concerning brain networks, specific changes have been found by Gour et. al, with a double dissociation in EOAD and LOAD between two networks implicated in cognitive functions (Gour et al., 2014). The consequences of neurodegeneration biomarker changes on remote areas, as a function of age, are still unknown. This can be addressed by functional MRI or PET connectivity studies. 
Our novel approach was to assess the whole brain volume of neurodegeneration biomarkers, namely atrophy (neuronal loss), and hypometabolism (synaptic activity). We hypothesized that the extent of these changes would vary according to age of onset. In fact, when observed at a specific time point, atrophy and hypometabolism reflect upstream processes of synaptic dysfunction and neuronal loss, which may both depend on the severity of the disease, cognitive reserve, and possibly other neurodegenerative processes that may have started before the disease onset.

Our results suggest that EOAD patients display almost 5 times more atrophic voxels than those of LOAD patients, but that metabolic level does not differ across patient groups. Thus, glucose metabolism appears to be more spared in EOAD than in LOAD patients, commensurate with their respective volumes of atrophy. We hypothesize that the volume of changes of these two biomarkers may be somehow affected by whole brain compensatory processes. Compensatory mechanisms are believed to take place in $\mathrm{AD}$ pathophysiology, and may be expressed by an increase of glucose metabolism level in response to atrophy (Villain et al., 2010). A greater increase of glucose metabolism, relative to the extent of atrophy, may exist in EOAD patients. It is worth mentioning, however, that educational level was similar in both patient groups. Since education is commonly considered to be a proxy of cognitive reserve, which can be viewed as a reduced susceptibility to impairment due to greater use of compensatory processes, our data suggest that educational level is unlikely to account for the differences observed in the current study. On the other hand, we observed higher atrophy levels in EOAD patients. Atrophy level and CSF markers of neurodegeneration (in particular Tau and phosphoTau) are looked upon as surrogate markers for neuronal loss and severity of neurodegenerative processes. Tau protein levels in CSF were similar in EOAD and LOAD 
patients, which suggest severe degeneration in both groups. Hence the question of possible neurodegeneration prior to AD pathology deposits in EOAD patients is open. Previous studies in patients with MCI showed that neurodegeneration can exist independently of amyloïdopathy, for example in the case of "Suspected non-Alzheimer disease Pathophysiology" patients (Jack et al., 2016). One way to further explore the hypothesis of a prior neurodegenerative state would be to extend this study to the prodromal stages of AD.Indeed, different degrees of neurodegeneration might be expected between early and lateonset MCI due to AD. Comparisons between different age groups in prodromal AD patients, or even in subjective cognitive impairment (SCI) patients, should be relevant and should contribute to better understand the different patterns of atrophy and metabolism at the dementia stage, and should provide further insights into the first stages of the disease. 
Ethical approval: This research has been approved by the local ethics CPP committee (“Comité de Protection des Personnes").

\section{Acknowledgments:}

None of the authors have any actual or potential conflicts of interest related to this work. The authors are thankful to the patients, their families and healthy controls for their generous participation in this study. They are grateful to Dr. Radka Gantcheva for clinical assessment of healthy subjects, Natalina Gour for neuropsychological assessment of patients, Dr Raphaelle Bernard for performing Apo E genotyping, Julie Pelat and Lucie Toulemonde (APHM, Direction Recherche Clinique) for their help with study management including data managing and Mohamed Fattalah (AP-HM, Centre d'Investigation Clinique) for his help with data managing.

\section{Funding:}

This work was supported by the French Hospital Clinical Research Program (PHRC ADAGE 2008-A01213-52), the A*MIDEX project ( $\mathrm{n}^{\circ}$ ANR-11-IDEX-0001-02) funded by the « Investissements d'Avenir » French Government program, managed by the French National Research Agency (ANR) and the association "déchaines ton coeur". Anne-Laure Aziz is supported by a Young Researcher allowance award from Toulouse Hospital, France. Lauréline Duprat is supported by a "Année-Recherche" award from the Aix-Marseille University. Sven Joubert was supported by a Chercheur-boursier Senior award from the Fonds de recherche du Québec - Santé (FRQS) and by the Alzheimer Society of Canada. 


\section{References:}

Barbeau, E., Didic, M., Tramoni, E., Felician, O., Joubert, S., Sontheimer, A., Ceccaldi, M., Poncet, M., 2004. Evaluation of visual recognition memory in MCI patients. Neurology 62, 13171322.

Benton, A.L., Varney, N.R., Hamsher, K.D., 1978. Visuospatial judgment. A clinical test. Arch. Neurol. 35, 364-367.

Binetti, G., Magni, E., Padovani, A., Cappa, S.F., Bianchetti, A., Trabucchi, M., 1993. Neuropsychological heterogeneity in mild Alzheimer's disease. Dementia 4, 321-326.

Bittner, D., Grön, G., Schirrmeister, H., Reske, S.N., Riepe, M.W., 2005. [18F]FDG-PET in patients with Alzheimer's disease: marker of disease spread. Dement Geriatr Cogn Disord 19, 24-30. doi:10.1159/000080967

Braak, H., Braak, E., 1991. Neuropathological stageing of Alzheimer-related changes. Acta Neuropathol. 82, 239-259.

Cardebat, D., Doyon, B., Puel, M., Goulet, P., Joanette, Y., 1990. [Formal and semantic lexical evocation in normal subjects. Performance and dynamics of production as a function of sex, age and educational level]. Acta Neurol Belg 90, 207-217.

Chételat, G., Desgranges, B., Landeau, B., Mézenge, F., Poline, J.B., de la Sayette, V., Viader, F., Eustache, F., Baron, J.-C., 2008. Direct voxel-based comparison between gray matter hypometabolism and atrophy in Alzheimer's disease. Brain 131, 60-71. doi:10.1093/brain/awm288

Cummings, J.L., 1997. The Neuropsychiatric Inventory: assessing psychopathology in dementia patients. Neurology 48, S10-16.

Davidson, Y., Gibbons, L., Pritchard, A., Hardicre, J., Wren, J., Stopford, C., Julien, C., Thompson, 
J., Payton, A., Pickering-Brown, S.M., Pendleton, N., Horan, M.A., Burns, A., Purandare, N., Lendon, C.L., Neary, D., Snowden, J.S., Mann, D.M.A., 2007. Apolipoprotein E epsilon4 allele frequency and age at onset of Alzheimer's disease. Dement Geriatr Cogn Disord 23, 60-66. doi:10.1159/000097038

Delay J, Brion S. Les démences tardives. Masson et Cie, Paris, 1962, n.d.

Deloche, G., Hannequin, D., Dordain, M., Metz-Lutz, M.N., Kremin, H., Tessier, C., Vendrell, J., Cardebat, D., Perrier, D., Quint, S., Pichard, B., 1997. Diversity of patterns of improvement in confrontation naming rehabilitation: some tentative hypotheses. J Commun Disord 30, 11-21; quiz 21-22.

Dubois, B., Slachevsky, A., Litvan, I., Pillon, B., 2000. The FAB: a Frontal Assessment Battery at bedside. Neurology 55, 1621-1626.

Fan, Y., Batmanghelich, N., Clark, C.M., Davatzikos, C., Alzheimer's Disease Neuroimaging Initiative, 2008. Spatial patterns of brain atrophy in MCI patients, identified via highdimensional pattern classification, predict subsequent cognitive decline. Neuroimage 39, 1731-1743. doi:10.1016/j.neuroimage.2007.10.031

Farrer, L.A., Cupples, L.A., Haines, J.L., Hyman, B., Kukull, W.A., Mayeux, R., Myers, R.H., Pericak-Vance, M.A., Risch, N., van Duijn, C.M., 1997. Effects of age, sex, and ethnicity on the association between apolipoprotein E genotype and Alzheimer disease. A meta-analysis. APOE and Alzheimer Disease Meta Analysis Consortium. JAMA 278, 1349-1356.

Folstein, M.F., Folstein, S.E., McHugh, P.R., 1975. "Mini-mental state". A practical method for grading the cognitive state of patients for the clinician. J Psychiatr Res 12, 189-198.

Freer, R., Sormanni, P., Vecchi, G., Ciryam, P., Dobson, C.M., Vendruscolo, M., 2016. A protein homeostasis signature in healthy brains recapitulates tissue vulnerability to Alzheimer's disease. Sci Adv 2, e1600947. doi:10.1126/sciadv.1600947

Frisoni, G.B., Pievani, M., Testa, C., Sabattoli, F., Bresciani, L., Bonetti, M., Beltramello, A., 
Hayashi, K.M., Toga, A.W., Thompson, P.M., 2007. The topography of gray matter involvement in early and late-onset Alzheimer's disease. Brain 130, 720-730. doi:10.1093/brain/awl377

Frisoni, G.B., Testa, C., Sabattoli, F., Beltramello, A., Soininen, H., Laakso, M.P., 2005. Structural correlates of early and late-onset Alzheimer's disease: voxel based morphometric study. J. Neurol. Neurosurg. Psychiatr. 76, 112-114. doi:10.1136/jnnp.2003.029876

Good, C.D., Johnsrude, I.S., Ashburner, J., Henson, R.N., Friston, K.J., Frackowiak, R.S., 2001. A voxel-based morphometric study of ageing in 465 normal adult human brains. Neuroimage 14, 21-36. doi:10.1006/nimg.2001.0786

Gour, N., Felician, O., Didic, M., Koric, L., Gueriot, C., Chanoine, V., Confort-Gouny, S., Guye, M., Ceccaldi, M., Ranjeva, J.P., 2014. Functional connectivity changes differ in early and lateonset Alzheimer's disease. Hum Brain Mapp 35, 2978-2994. doi:10.1002/hbm.22379

Grober, E., Buschke, H., Crystal, H., Bang, S., Dresner, R., 1988. Screening for dementia by memory testing. Neurology 38, 900-903.

Jack, C.R., Knopman, D.S., Chételat, G., Dickson, D., Fagan, A.M., Frisoni, G.B., Jagust, W., Mormino, E.C., Petersen, R.C., Sperling, R.A., van der Flier, W.M., Villemagne, V.L., Visser, P.J., Vos, S.J.B., 2016. Suspected non-Alzheimer disease pathophysiology--concept and controversy. Nat Rev Neurol 12, 117-124. doi:10.1038/nrneurol.2015.251

Joubert, S., Gour, N., Guedj, E., Didic, M., Guériot, C., Koric, L., Ranjeva, J.-P., Felician, O., Guye, M., Ceccaldi, M., 2016. Early-onset and late-onset Alzheimer's disease are associated with distinct patterns of memory impairment. Cortex 74, 217-232. doi:10.1016/j.cortex.2015.10.014

Kalpouzos, G., Eustache, F., de la Sayette, V., Viader, F., Chételat, G., Desgranges, B., 2005. Working memory and FDG-PET dissociate early and late-onset Alzheimer disease patients. J. Neurol. 252, 548-558. doi:10.1007/s00415-005-0685-3 
Koedam, E.L.G.E., Lauffer, V., van der Vlies, A.E., van der Flier, W.M., Scheltens, P., Pijnenburg, Y.A.L., 2010. Early-versus late-onset Alzheimer's disease: more than age alone. J. Alzheimers Dis. 19, 1401-1408. doi:10.3233/JAD-2010-1337

McKhann, G.M., Knopman, D.S., Chertkow, H., Hyman, B.T., Jack, C.R., Kawas, C.H., Klunk, W.E., Koroshetz, W.J., Manly, J.J., Mayeux, R., Mohs, R.C., Morris, J.C., Rossor, M.N., Scheltens, P., Carrillo, M.C., Thies, B., Weintraub, S., Phelps, C.H., 2011. The diagnosis of dementia due to Alzheimer's disease: recommendations from the National Institute on AgingAlzheimer's Association workgroups on diagnostic guidelines for Alzheimer's disease. Alzheimers Dement 7, 263-269. doi:10.1016/j.jalz.2011.03.005

Montgomery, S.A., Smeyatsky, N., de Ruiter, M., Montgomery, D.B., 1985. Profiles of antidepressant activity with the Montgomery-Asberg Depression Rating Scale. Acta Psychiatr Scand Suppl 320, 38-42.

Murray, M.E., Graff-Radford, N.R., Ross, O.A., Petersen, R.C., Duara, R., Dickson, D.W., 2011. Neuropathologically defined subtypes of Alzheimer's disease with distinct clinical characteristics: a retrospective study. Lancet Neurol 10, 785-796. doi:10.1016/S14744422(11)70156-9

Reitan, R.M., 1955. The relation of the trail making test to organic brain damage. J Consult Psychol 19, 393-394.

Rey, A., de MORSIER, null, 1960. [Test for the examination of constructional apraxia]. Rev. Neurol. (Paris) 102, 653-656.

Salmon, E., Collette, F., Degueldre, C., Lemaire, C., Franck, G., 2000. Voxel-based analysis of confounding effects of age and dementia severity on cerebral metabolism in Alzheimer's disease. Hum Brain Mapp 10, 39-48.

Schmidt, R., Petrovic, K., Ropele, S., Enzinger, C., Fazekas, F., 2007. Progression of leukoaraiosis and cognition. Stroke 38, 2619-2625. doi:10.1161/STROKEAHA.107.489112 
Slooter, A.J., Cruts, M., Kalmijn, S., Hofman, A., Breteler, M.M., Van Broeckhoven, C., van Duijn, C.M., 1998. Risk estimates of dementia by apolipoprotein E genotypes from a populationbased incidence study: the Rotterdam Study. Arch. Neurol. 55, 964-968.

Smits, L.L., Pijnenburg, Y.A.L., van der Vlies, A.E., Koedam, E.L.G.E., Bouwman, F.H., Reuling, I.E.W., Scheltens, P., van der Flier, W.M., 2015. Early-onset APOE E4-negative Alzheimer's disease patients show faster cognitive decline on non-memory domains. Eur Neuropsychopharmacol 25, 1010-1017. doi:10.1016/j.euroneuro.2015.03.014

Thambisetty, M., An, Y., Tanaka, T., 2013. Alzheimer's disease risk genes and the age-at-onset phenotype. Neurobiol. Aging 34, 2696.e1-5. doi:10.1016/j.neurobiolaging.2013.05.028

Thomas-Antérion, C., Collomb, K., Borg, C., Nevers, B., Laurent, B., 2006. [Evaluation of memory for French public events: EVE-30 in 108 controls, 10 mild cognitively impaired and 10 Alzheimer's disease patients]. Rev. Neurol. (Paris) 162, 1232-1239.

Van der Linden, M., Juillerat, A.-C., 2004. [Neuropsychological rehabilitation in early stage Alzheimer's disease: principles, methods and perspectives]. Rev. Neurol. (Paris) 160, S64-70. Villain, N., Chételat, G., Desgranges, B., Eustache, F., 2010. Neuroimaging in Alzheimer's disease: a synthesis and a contribution to the understanding of physiopathological mechanisms. Biol Aujourdhui 204, 145-158. doi:10.1051/jbio/2010010

Zarit, S.H., Reever, K.E., Bach-Peterson, J., 1980. Relatives of the impaired elderly: correlates of feelings of burden. Gerontologist 20, 649-655.

\section{TABLES AND FIGURES:}

\section{Tables:}

Table 1: Epidemiological, neuropsychiatric and quality of life assessment in patients and controls.

Table 2: Apolipoprotein E genotype and cerebrospinal fluid biomarkers in patients and controls. 
Table 3: Results on neuropsychological assessment in patients and controls.

Table 4: Comparison of neuropsychological Z-scores between EOAD and LOAD patients.

Table 5: Statistics and localization of the most significant results of intergroup PET and MRI comparisons between patients and their respective healthy controls.

\section{Figures:}

Fig. 1: Results of an intergroup comparison between EOAD and LOAD patients for metabolic and atrophic data: $3 \mathrm{D}$ renders.

Fig. 2: Results of an intergroup comparison between patients and matched controls for metabolic and atrophic data: 3D renders and axial slices.

Fig. 3: 3D renders and axial slices for EOAD (A) and LOAD patients (B), showing pure atrophic regions (blue), pure hypometabolic regions (red) or both atrophic and hypometabolic regions (pink) for the whole brain.

Fig. 4: Volume of neurodegenerative lesions (atrophy and hypometabolism) in the whole cortex, in $\mathrm{mm} 3$, for EOAD and LOAD patients. 


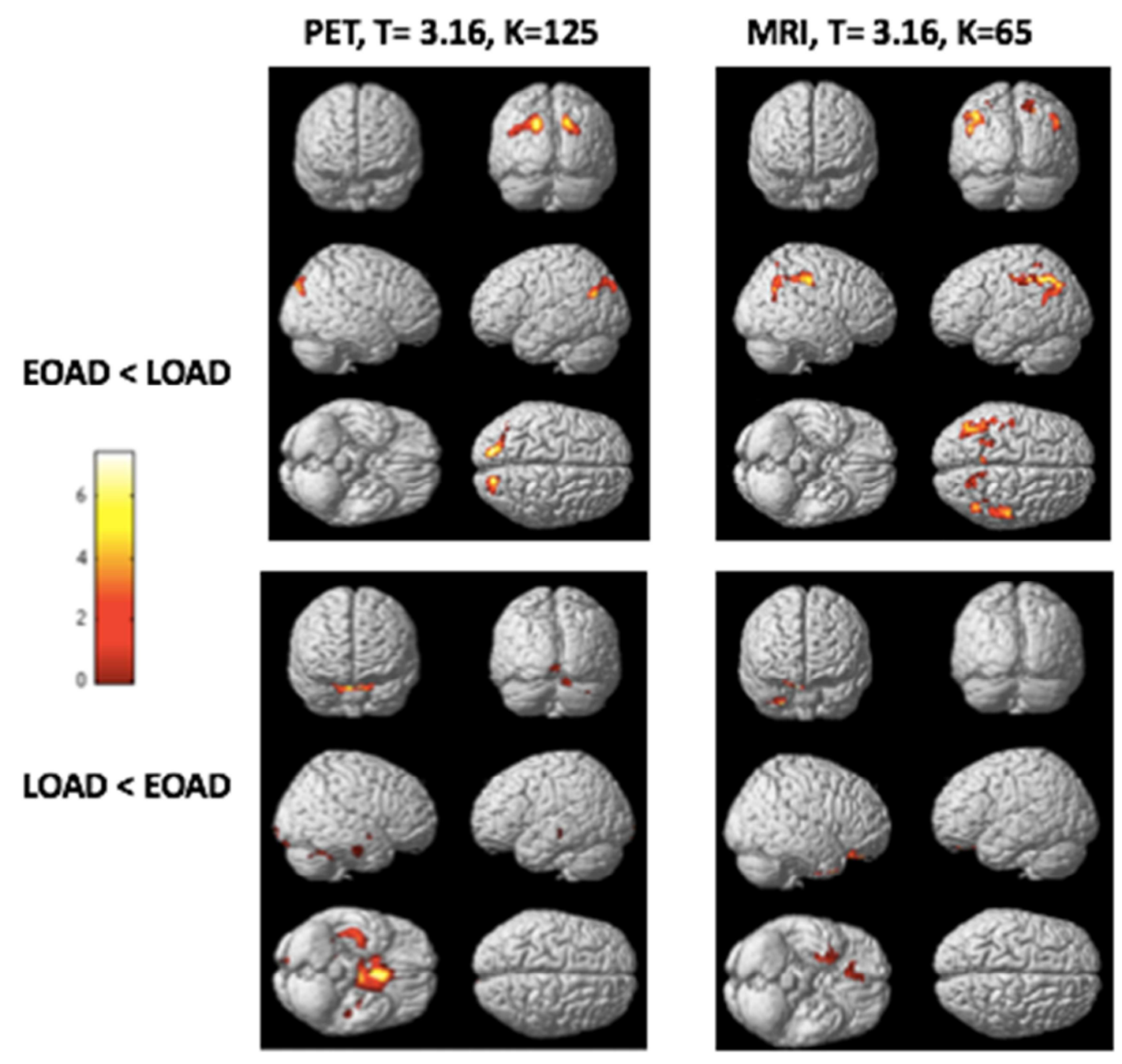

Fig. 1: Results of intergroup comparison between EOAD and LOAD patients for metabolic and atrophic data: $3 D$ renders.

$\mathrm{T}$-score $=3.16$, cluster size $\mathrm{k}>125$ voxels for PET and $>65$ voxels for MRI.

In EOAD, hypometabolism is more pronounced in bilateral cuneus, in left precuneus (BA 19) and in right middle temporal gyrus. In LOAD, hypometabolism is more pronounced in right parahippocampus (BA 28) and right inferior temporal gyrus (BA 20).

In EOAD, atrophy is more pronounced in bilateral inferior (BA 40) and superior (BA 7) parietal lobule, in bilateral post central gyrus (BA 2) and in middle temporal gyrus (BA 39). In LOAD, atrophy is more pronounced in right orbito-frontal gyrus (BA 11), in right inferior (BA 20) and superior temporal gyrus (BA 38). 


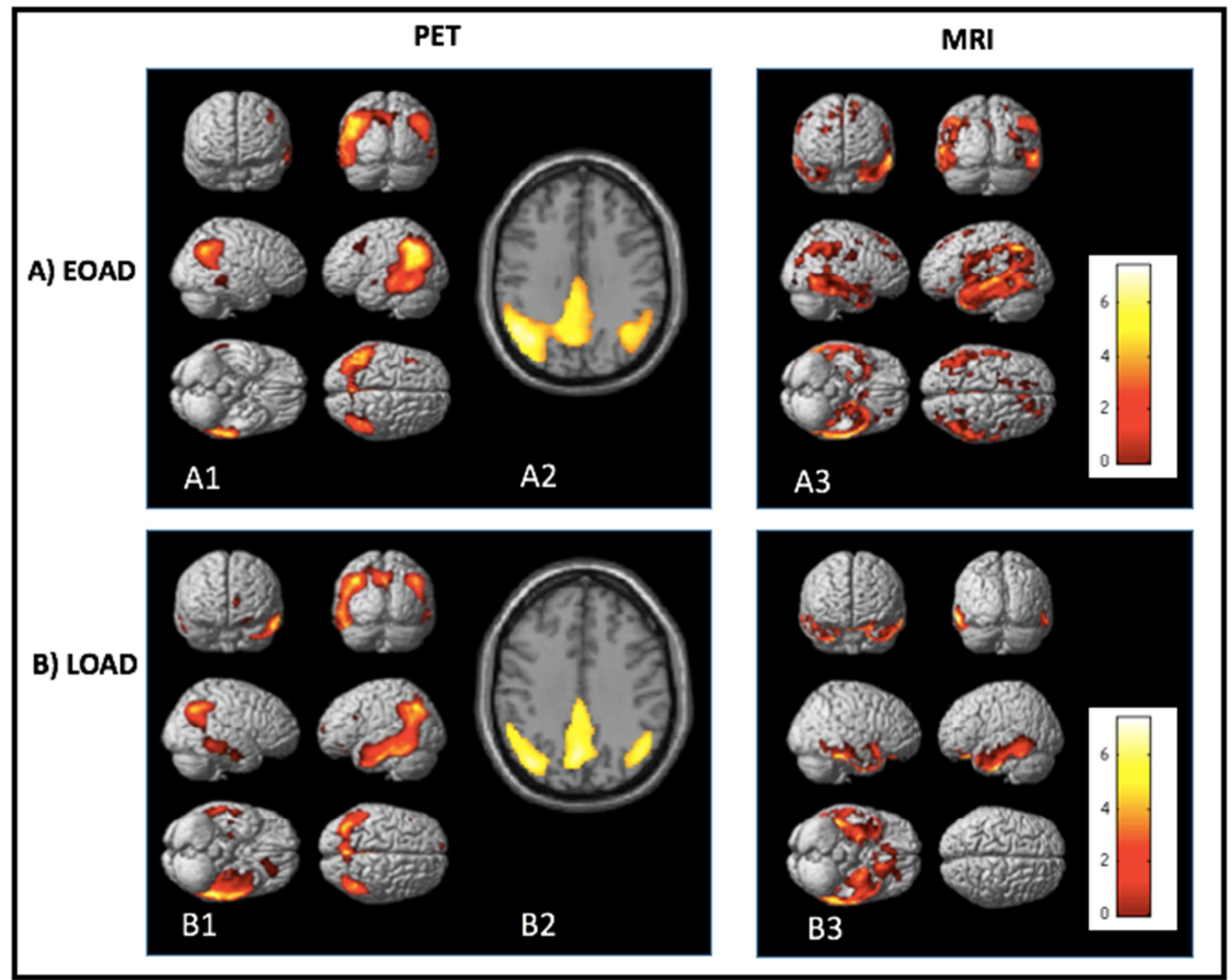

Fig. 2: Results of intergroup comparison between patients and their matched controls for metabolic and atrophic data: $3 D$ renders and axial slices.

False-Discovery Rate, T-score $=3.16$, k> 300 voxels. In EOAD, hypometabolism involves the temporo-parietal bilateral junction and the cingulate posterior cortex. In LOAD, it concerns the same regions as well as bilateral temporal areas (anterior and middle temporal areas). In EOAD, atrophy is diffuse, involving the prerolandic and retrorolandic associative neocortex. In LOAD patients, bilateral temporal atrophy is observed, without significant atrophy in neocortical areas. 
A) EOAD
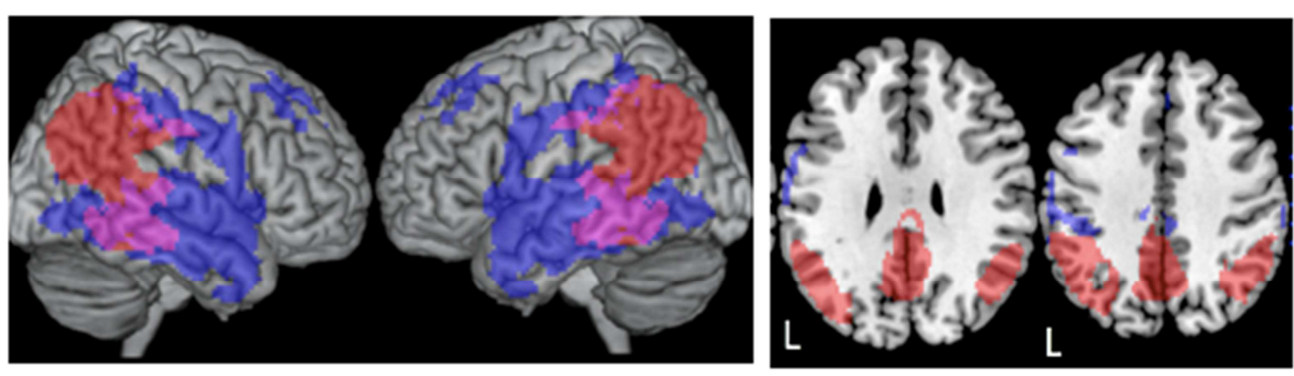

B) LOAD
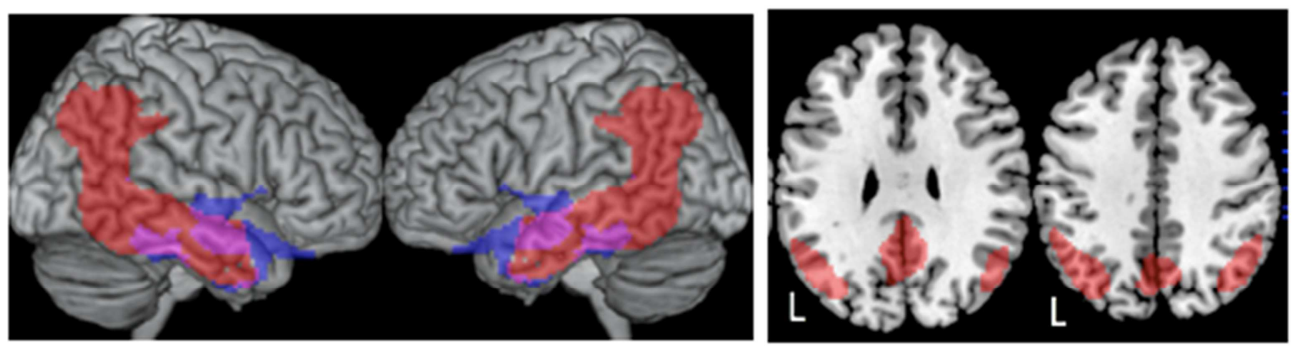

Fig.3: 3D renders and axial slices for EOAD (A) and LOAD patients (B), showing pure atrophic regions (blue), pure hypometabolic regions (red) or both atrophic and hypometabolic regions (pink) for the whole brain. Significance level is defined for a minimal $T$-score of 3.16 with a cluster minimal size of 300 contiguous voxels. $L=$ left.

In EOAD and LOAD patients, pure hypometabolic regions (in red) are the bilateral temporoparietal junctions and the posterior cingulate/precuneus cortex. The posterior and anterior temporal regions are hypometabolic only in LOAD patients. In EOAD patients, pure atrophic regions (in blue) are the temporal and frontal regions, whereas it is limited to temporal structures in LOAD patients. Regions showing both significant hypometabolism and atrophy (in pink) are the bilateral posterior temporal regions in EOAD patients, and middle temporal regions in LOAD patients. 


\section{Volume of neurodegenerative lesions for the whole brain (mm3)}

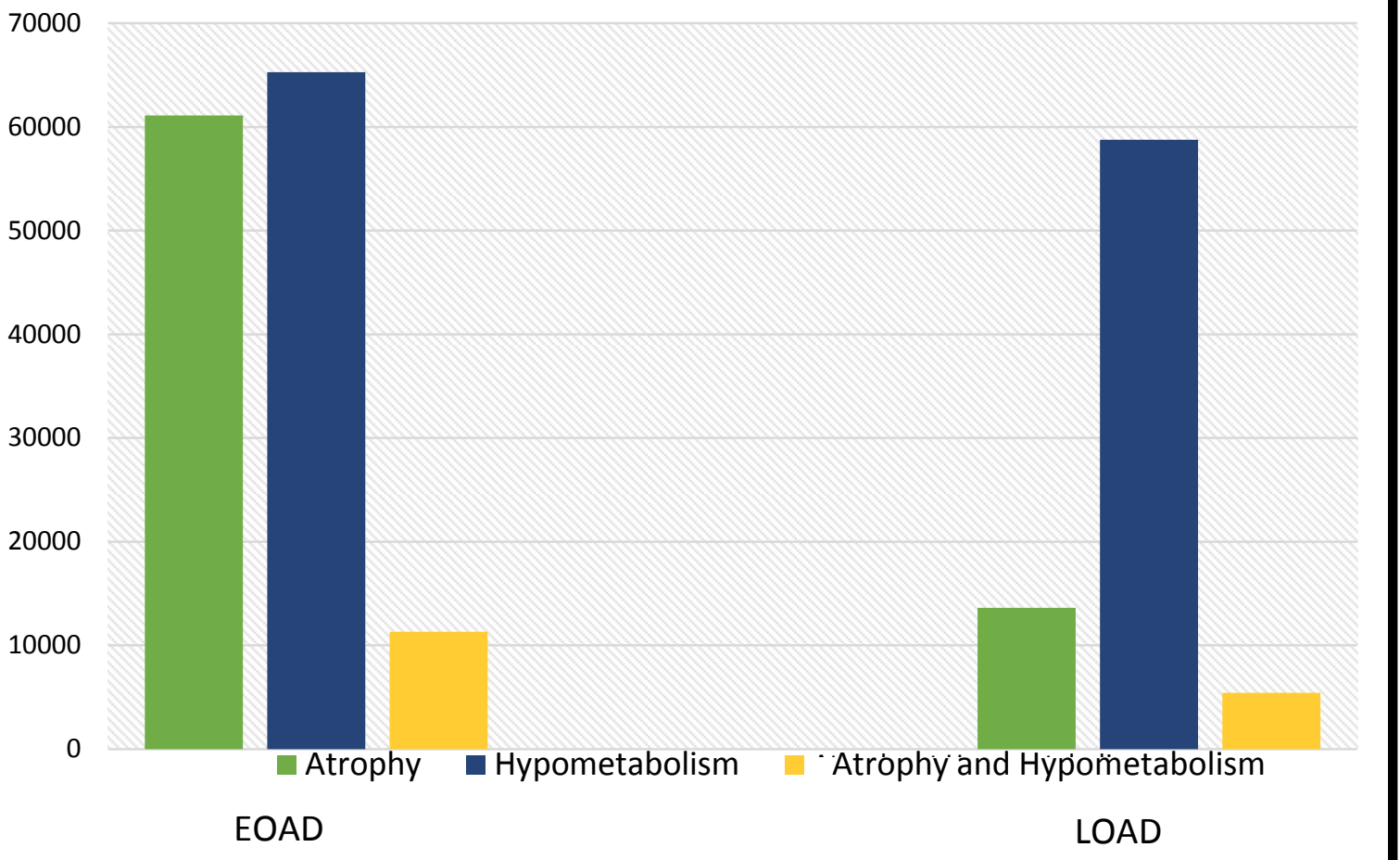

Fig. 4: Volume of neurodegenerative change (atrophy and hypometabolism) in the whole cortex, in mm3, for EOAD and LOAD patients.

There is a dissociation between the total hypometabolic volume (near to $59000 \mathrm{~mm}^{3}$ ) and the atrophic volume (near to $14000 \mathrm{~mm}^{3}$ ) in LOAD patients. In EOAD patients, the volumes of atrophy or hypometabolism are quite similar, respectively of 61000 and $65000 \mathrm{~mm}^{3}$. Both atrophic and hypometabolic regions involve about $11000 \mathrm{~mm}^{3}$ in EOAD patients and 5400 $\mathrm{mm}^{3}$ in LOAD patients. 
Highlights:

- Hypometabolism is similar in topography and volume in EOAD and LOAD patients.

- Atrophy is limited to temporal areas in LOAD patients and widespread in EOAD ones.

- Greater atrophy extent in EOAD could be related to different pathophysiological processes. 